UDK 528.48

\title{
MEASUREMENT OF VERTICALITY CONSTRUCTION OF BUSHINGS FOR LABORATORY CONSTRUCTION MATERIALS
}

\author{
Petr JADVIŠČOK ${ }^{1}$, Rostislav DANDOŠ ${ }^{2}$, Tomáš JIROUŠEK ${ }^{3}$ \\ Institute of Geodesy and Mine Surveying, Faculty of Mining and Geology, VSB - Technical University \\ of Ostrava, 17.listopadu 15, CZ 70833 Ostrava, Czech Republic \\ E-mails: ${ }^{1}$ petr.jadviscok.st1@vsb.cz (corresponding author); ${ }^{2}$ rostislav.dandos@vsb.cz; \\ 3tomas.jirousek.st@vsb.cz
}

Received 10 September 2014; accepted 28 November 2014

\begin{abstract}
This contribution describes process which was used for verticality measurement of the bushings for laboratory construction materials in the pavilion of testing. This pavilion is newly built in VŠB-TU Ostrava, Faculty of Civil Engineering, as part of the Testing house of the building materials. The requirement of the building investor was to determine the verticality of the bushings placed between the first aboveground and the first underground floor. After the building finishing, the bushings with the diameter $70 \mathrm{~mm}$ will be used for loading tests of various building materials. The final number of bushings is 169 , and they are placed lengthwise and crosswise in the step of $750 \mathrm{~mm}$. The centres of the bushings were measured by polar method in pavilion local coordinate system. The precision of the bushing centres determination was $\pm 5 \mathrm{~mm}$ according to the investor's requirement. The precision would not be followed if the standard equipment for reflector fixing was used. In that case, it was necessary to design and manufacture special tool in the shape of truncated cone. On the top part was placed central pivot for reflector with additional plate bubble.
\end{abstract}

Keywords: verticality, bushing, tool, CAD drawing, Leica TS30.

\section{Introduction}

Geodetic activities associated with alignment and verticality evaluation are quite frequent in engineering geodesy. The meeting of vertical geometric parameters of buildings, construction components or technical equipment is as important, and in some cases even more important, as the meeting of horizontal dimensions and shapes. Verticality is primarily critical for the functionality of facilities and their safety and operability. In the industrial area, the verticality parameter of industrial equipment of machinery installed in vertical structures is even more critical. The operation of such equipment strongly depends on highly accurate alignment (polarizing).

\section{The measuring subject and more detailed task specification}

The polarization process concerned a set of construction components - vertical bushings. The bushings are embedded in the first above-ground floor's structure; therefore, the first underground floor's ceiling of the construction material testing facility. The specified facility has been designed for load tests to be completed at the Faculty of Civil Engineering of VŠBTU Ostrava.

The requirement of the building investor was to determine the verticality of the bushings placed between the first above-ground and the first underground floors of the construction material testing facility. The bushings are in profiles with $750 \mathrm{~mm}$

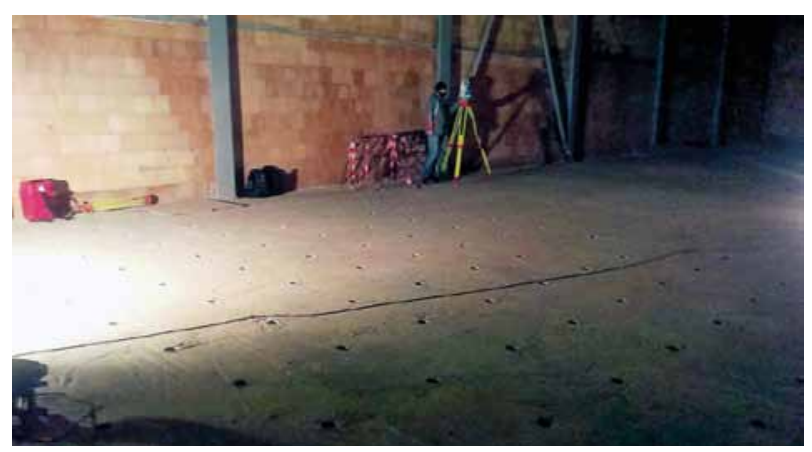

Fig. 1. Construction material testing facility 
spacing. Every profile features thirteen bushings. A total of 169 bushings form a symmetrical grid. The bushings and their layout are shown in Figure 1.

\section{Measuring precision analysis}

During highly accurate geodetic activities, it is necessary to analyse measuring precision. The measuring precision analysis main goal is to determine a suitable measuring method and select equipment, including aids. The investor has set its bushing centre polarization precision to $\pm 5 \mathrm{~mm}$ in location. The following precision analysis is based on the polar method and the maximum measured length of $30 \mathrm{~m}$. Since the measuring was to be completed within a local system, the impact of foundation on precision has not been considered. The precision analysis only applies to the precision of the measured values. The precision analysis is based on the same impact of the measured angle and the measured length on local precision (Černota et al. 2011).

Formula for the precision of the point location determination through the polar method:

$$
m_{P}^{2}=m_{S}^{2}+s^{2} \cdot\left(\frac{m_{\omega}}{\rho}\right)^{2} .
$$

Required precision: $\mathrm{m}_{\mathrm{p}}=5 \mathrm{~mm}$.

The maximum expected measured length: $\mathrm{s}=30 \mathrm{~m}$,

$$
\begin{array}{ll}
\frac{m_{P}^{2}}{2}=m_{S}^{2} & \frac{m_{P}^{2}}{2}=s^{2} \cdot\left(\frac{m_{\omega}}{\rho}\right)^{2} \\
m_{S}=\sqrt{\frac{m_{P}^{2}}{2}} & m_{\omega}=\sqrt{\frac{m_{P}^{2} \cdot \rho^{2}}{2 \cdot s^{2}}} \\
m_{S}=\sqrt{\frac{5^{2}}{2}} & m_{\omega}=\sqrt{\frac{5^{2} \cdot \rho^{2}}{2 \cdot 30^{2}}} \\
m_{S}=3.5 \mathrm{~mm} & m_{\omega}=7.5 \mathrm{mgon}
\end{array}
$$

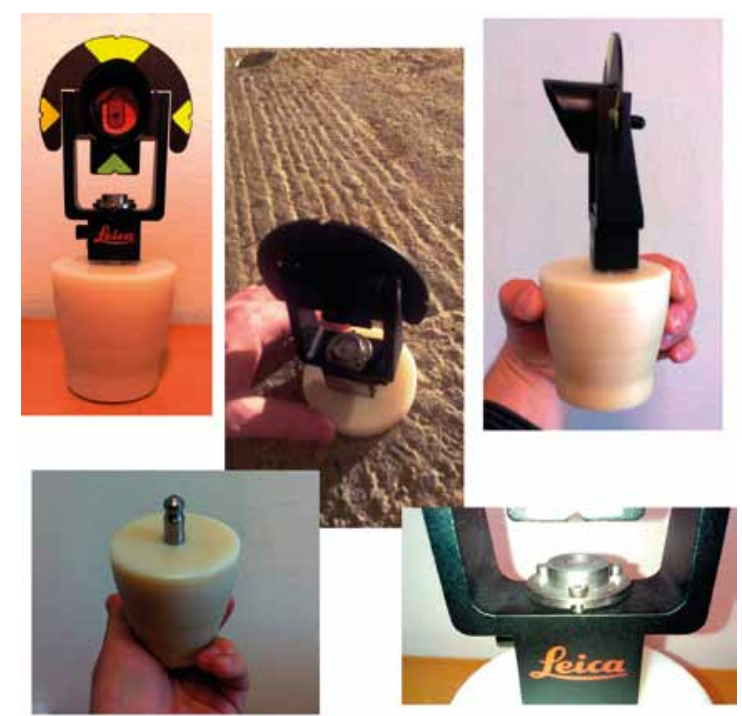

Fig. 2. Proposed truncated cone + Leica GPM 101 Professional
The completed measuring precision analysis has shown that the following precision levels must be observed in order to achieve the required location precision of the polarized points. The measured lengths must feature precision based on the maximum acceptable a mean square error $m_{s}=3.5 \mathrm{~mm}$. The measured angles may feature the maximum a mean square error error $m_{\omega}=7.5 \mathrm{mgon}$. For analysis of the accuracy was applied the principle of equal influence. Based on the analysis, the Leica TS 30 total station has been selected for the geodetic works since it fully meets the specified polarization precision requirements.

The Leica TS30 total station measures angles with precision $m_{\omega}=0.5$ mgon. While applying the standard mode, lengths may be measured with precision $m_{s}=1+1 \mathrm{ppm}$. However, the declared length measuring precision may only be achieved when precise reflecting prisms made by the same manufacturers are used. The Leica GMP101 Professional reflective mini prism designed for precise measuring was used during the geodetic works. The total station's regular accessories (stake with reflective equipment) might not have achieved the required level of precision. The measuring would have been negatively impacted by the positioning of the stake in the polarized bushings (Pospiśilová et al. 2012). That is why we designed a special truncated cone, which replaced the stake. The cone dimensions were proportional to the polarized bushing diameter. The cone is made of hardened silicone. Figure 2 shows the special cone.

We could have used a lower precision category instrument to achieve the required level of angle measuring precision; however, the length measuring precision would have been a problem. That was the reason why we have selected the Leica TS30 total station, which measures lengths with high precision.

\section{Measuring methodology}

The polar method was used to measure bushing verticality. The key thing in determining bushing verticality was to determine the locations of the bushing centres on the first above-ground floor and the first underground floor of the construction material testing facility (Gasinec et al. 2012).

A local system of coordinates was selected for polarization and subsequent data processing. The coordinate axis orientations were defined in line with the facility's orientation. However, a uniform local system of coordinates was necessary to determine bushing verticality through the comparison of the locations 
of bushing centres on the above-ground and underground floors. The principle of connecting the underground floor to the local system of coordinates is shown in Figure 3 (Černota et al. 2011).

Three bushings were conveniently selected on the facility's above-ground floor (total station $+2 \times$ tripod with reflective prism - see Figure 3). The three points formed a polarization grid, enabling the polarization of the other bushings. Identical point configuration on the underground floor was based on the projection of points to the underground floor through the bushings. The three projected points were stabilized on the underground floor in order to complete polarization on the underground floor in the same configuration (position - orientation) and to merge the measurements completed on both floors (Pospíśilová et al. 2012). Figure 4 shows the principle of projecting the polarization grid points to the underground floor.

The bushing centres were polarized through the Leica GMP101 Professional reflective mini prism, which was placed on a special truncated cone. The cone with the prism was repeatedly inserted into the bushing opening, and the cone was balanced by means of a level. Polarization was completed. A similar process was completed during the subsequent bushing centre polarization on the facility's underground floor. The cone with the prism was repeatedly inserted into the bushings in the first aboveground floor's ceiling. Figure 5 shows the geodetic works during the polarization of bushings on the underground floor.

\section{Calculations and graphic documentation processing}

The GROMA v. 7 geodetic software was used to process and analyse the measured data. The vertical parameters of the individual bushings were determined through the comparison of the locations of bushing centres on the above-ground and underground floors of the subject facility. Figure 6 below shows an example of bushing verticality numerical evaluation.

The AutoCAD 2014 program was used to produce graphic documentation. Based on the building investor's request, the bushing verticality was graphically expressed through the graphical comparison of bushing centre locations. The graphic documentation primarily supports one's initial understanding of the verticality of the individual bushings. Figure 7 shows a graphic output of the AutoCAD 2014 program.

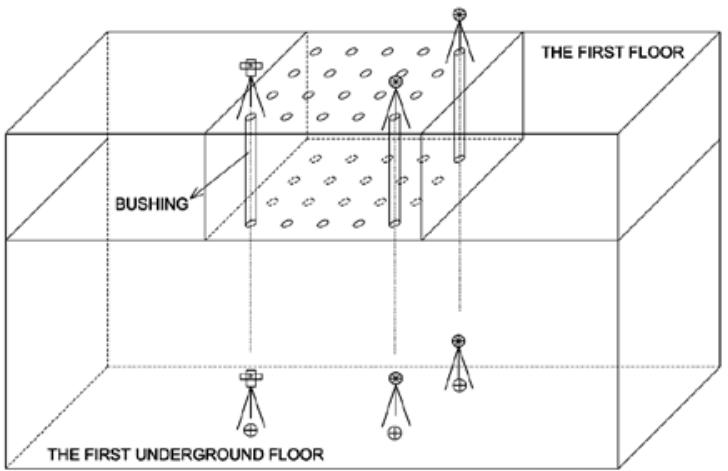

Fig. 3. Diagram of the first underground floor connection

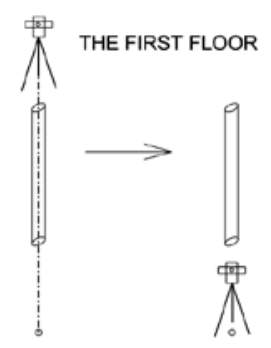

THE FIRST UNDERGROUND FLOOR

Fig. 4. The principle of point projections to the facility's underground floor

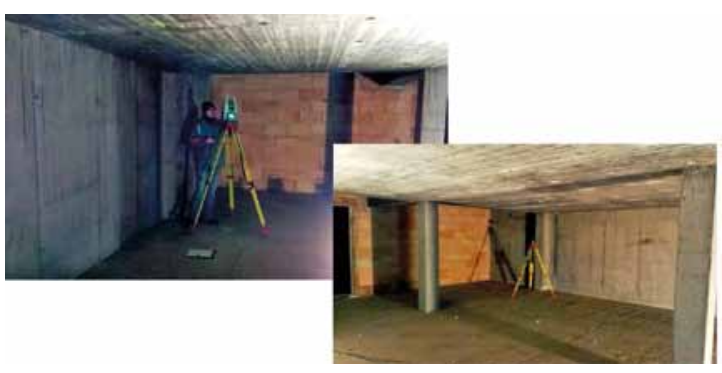

Fig. 5. Polarization in the facility's underground floor

\begin{tabular}{|c|c|c|c|c|c|c|c|}
\hline PONT & $d Y$ & $d x$ & $\mathrm{dz}$ & $\operatorname{sxy}$ & dPol & АЕмитн & NOTE \\
\hline 1 & 0.003 & 0.002 & & 0.003 & 0.004 & 262.5666 & \\
\hline 2 & 0.004 & 0.003 & & 0.004 & 0.005 & 259.0334 & \\
\hline 3 & 0.003 & -0.004 & & 0.004 & 0.005 & 359.0334 & \\
\hline 4 & 0.020 & 0.003 & & 0.014 & 0.020 & 290.5214 & xoox \\
\hline 5 & 0.004 & 0.008 & & 0.006 & 0.009 & 229.5167 & $? ? ?$ \\
\hline 6 & 0.010 & 0.012 & & 0.011 & 0.016 & 244.2284 & $x x x$ \\
\hline 7 & 0.005 & 0.003 & & 0.004 & 0.006 & 265.5958 & \\
\hline
\end{tabular}

Fig. 6. Bushing verticality evaluation (example)

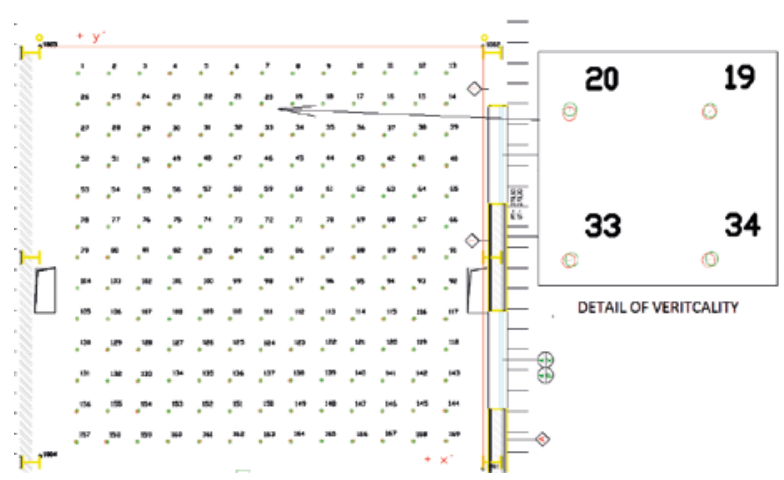

Fig. 7. Example of bushing verticality graphic evaluation 


\section{Conclusions}

The article describes the geodetic works associated with the determination of verticality of construction components installed in the floor system of the construction material testing facility. The building investor wished to determine the verticality of bushings, connecting the first above-ground floor and the first underground floor of the construction material testing facility. Based on the measuring precision analyses, a suitable method and equipment meeting the required precision levels were selected to achieve the required precision level. A special aid, which replaced a tripod, was designed to complete the geodetic works. Numerical documentation that contains the comparisons of the bushing centre locations on the facility aboveground and underground floors supports verticality evaluation. The numerical evaluation is supplemented with the images of bushing centre locations.

This article was written in connection with grant project SGS No. SP2014/148 - Creation of a detailed model quasigeoid the northeastern Moravia and Silesia and SGS No. SP2014/13 - The use of UAV device for creating $3 \mathrm{D}$ models in geodetic practice.

\section{References}

Černota, P.; Staňková, H.; Fecko, P.; Pospíšil, J.; Bedrunka, M. 2011. Connecting and orientation of the horizon of mine workings, in 11th International Multidisciplinary Scientific Geoconference (Sgem 2011), 2011, Albena, Bulgaria, vol. I, 735-742. ISSN: 1314-2704 (Print).
Pospíšilová, L.; Pospíšil, J.; Staňková, H. 2012. Micro-network creation in industrial surveying, Geodesy and Cartography 38(2) 70-74. ISSN: 2029-6991 print, ISSN 2029-7009 online. http://dx.doi.org/10.3846/20296991.2012.692216

Gasinec, J.; Gasincova, S.; Černota, P.; Stankova, H. 2012. Uses of terrestrial laser scanning in monitoring of ground ice within Dobšinska Ice Cave, Zastosowanie naziemnego skaningu laserowego do monitorowania lodu gruntowego $w$ Dobszyńskiej Jaskini Lodowej, Inzynieria Mineralna 30(2): 31-42. ISSN 1640-4920. Available from Internet: http:// www.potopk.republika.pl/an_archiwum.html

Petr JADVIŠČOK. Ing., VŠB - TU Ostrava, Institute of Geodesy and Mine Surveying, Faculty of Mining and Geology, VSB - Technical University of Ostrava, 17.listopadu 15, CZ 708 33 Ostrava, Czech Republic.Ph+420724087561, e-mail: petr.jadviscok.st1@vsb.cz

Research interest: the issues of precision GNSS technology in surveying practice.

Rostislav DANDOŠ. Ing., PhD, VŠB - TU Ostrava, Institute of Geodesy and Mine Surveying, Faculty of Mining and Geology, VSB - Technical University of Ostrava, 17.listopadu 15, CZ 708 33 Ostrava, Czech Republic. Ph+42059732 3263, e-mail: rostislav.dandos.st@vsb.cz

Research interest: measurement and evaluation of the movements and deformations of the retaining wall.

Tomáš JIROUŠEK. Ing., VŠB - TU Ostrava, Institute of Geodesy and Mine Surveying, Faculty of Mining and Geology, VSB - Technical University of Ostrava, 17.listopadu 15, CZ 708 33 Ostrava, Czech Republic.Ph+420597325269, e-mail: tomas. jirousek.st@vsb.cz

Research interest: the use of UAV device for creating 3D models in geodetic practice. 